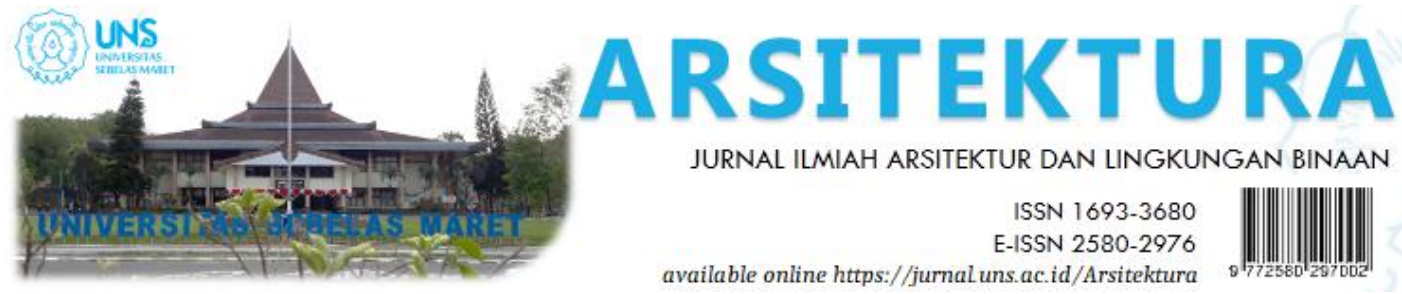

Volume 17 Issue 2 October 2019, pages:203-210

\title{
Penerapan Kajian Arsitektur Hijau dalam Strategi Perancangan Terminal Bus dan Pusat Perbelanjaan di Kabupaten Karanganyar
}

\section{The Application of Green Architecture Studies for Design Strategy in Bus Station and Shopping Center in Karanganyar}

\author{
Russiana Wahyu U.S. ${ }^{1 *}$, Agung Kumoro Wahyuwibowo ${ }^{2}$, Maya Andria Nirawati ${ }^{3}$ \\ Program Studi Arsitektur, Fakultas Teknik, Universitas Sebelas Maret ${ }^{1}$ \\ Email : $\underline{\text { russiana50@gmail.com* }}$ \\ Program Studi Arsitektur, Fakultas Teknik, Universitas Sebelas Maret ${ }^{2}$ \\ Program Studi Arsitektur, Fakultas Teknik, Universitas Sebelas Maret ${ }^{3}$
}

DOI: https://doi.org/10.20961/arst.v17i2.24422

Received:October 4, 2018 Revised: October 11, 2018 Accepted: March 30, 2019 Available online:October 31, 2019

\begin{abstract}
Land transportation, especially buses, plays an important role in community activities. The number of people who use buses will increase the number of buses. With the increase in the number of buses, a bus station that can accommodate adequate fleets and passengers is needed. In Karanganyar District there are 10 bus stations available but none of them are able to accommodate passengers and fleets with adequate facilities. The Government of Karanganyar has planned the development of the 2013-2032 Karanganyar Spatial Plan in the form of bus stations. One of them is located in Kebakkramat Sub-district. Bus station optimization can be combined with the existence of a shopping center as a support for activities and can be utilized by the people in surrounding areas to fulfill their needs. Bus stations and shopping centers are public facilities with high vehicle intensity and located in industrial locations which cause pollution. The green architecture approach is used as a design strategy to overcome problems and increase public awareness of the importance of caring for the environment. From this phenomenon, literature and field data are collected. Then, they are analyzed and discussed in accordance with the principles of green architecture based on criteria and benchmarks of the Green Building Council Indonesia. It is conducted to be applied to the selection of site locations, green architecture in building design, and utility systems.
\end{abstract}

Keywords: bus station, shopping center, green architecture

\section{PENDAHULUAN}

Transportasi darat berperan penting dalam aspek sosial, ekonomi, dan lingkungan (Dina, 2014). Hal tersebut dikarenakan segala aktivitas masyarakat membutuhkan pergerakan yang menggunakan transportasi khususnya transportasi darat (Sutandi, 2015). Salah satu alternatif transportasi darat yang dibutuhkan adalah bus. Untuk menggunakan jasa bus, dibutuhkan prasarana yang aman dan nyaman serta mudah diakses agar penumpang tidak menunggu bus di pinggir jalan. Setiap kota atau kabupaten di Indonesia biasanya memiliki terminal yang digunakan untuk sarana 
penghubung dalam kota, antar kota, maupun antar negara dengan tipe terminal yang sesuai dengan cakupan area yang dilayani (Prisamsiwi, Santosa, \& Pramesti, 2015). Di Kabupaten Karanganyar telah terdapat 10 terminal, namun dari seluruh terminal belum tersedia terminal induk maupun terminal yang dapat menampung penumpang dan armada dengan skala yang besar. Seiring bertambahnya jumlah penduduk dan kendaraan yang ada di Kabupaten Karaganyar, dibutuhkan pembangunan fasilitas yang memudahkan pengguna khususnya dalam hal transportasi dan pemenuhan kebutuhan sehari-hari. Pemerintah Kabupaten Karanganyar juga merencanakan pembangunan jangka panjang yang tertera dalam RTRW Kabupaten Karanganyar tahun 2013-2032 berupa terminal di beberapa daerah salah satunya di Kecamatan Kebakkramat.

Pengoptimalan terminal dapat dipadukan dengan adanya pusat perbelanjaan sebagai pendukung kegiatan di terminal. Penumpang yang menunggu jadwal keberangkatan atau membutuhkan oleh-oleh dapat memanfaatkan fasilitas pusat perbelanjaan. Masyarakat di Kabupaten Karanganyar dan sekitarnya juga dapat memanfaatkan pusat perbelanjaan untuk memenuhi kebutuhan dan hiburan. Terminal bus dan pusat perbelanjaan berpotensi tinggi untuk direncanakan di Kecamatan Kebakkramat dengan mempertimbangkan faktor-faktor tersebut.

Terminal bus dan pusat perbelanjaan yang direncanakan adalah fasilitas publik dengan intensitas kendaraan yang tinggi serta berada di lokasi industri, sehingga menimbulkan polusi yang dapat mempengaruhi ketidaknyamanan dan kesehatan pengguna. Pengguna membutuhkan fasilitas publik yang nyaman ketika mereka melakukan suatu kegiatan. Kenyamanan dapat diciptakan dengan desain yang responsif terhadap iklim dan ramah lingkungan (Dewi, Nirawati, \& Handayani, 2015). Pendekatan arsitektur hijau digunakan sebagai strategi desain perencanaan dan perancangan guna mengatasi permasalahan tersebut dan untuk meningkatkan kesadaran pengguna akan pentingnya rasa peduli terhadap lingkungan.

\subsection{Arsitektur Hijau}

Arsitektur hijau adalah proses perancangan bangunan dengan mengurangi penggunaan sumber daya energi, mengurangi dampak negatif bangunan terhadap lingkungan, meningkatkan kenyamanan pengguna, menghemat penggunaan lahan, dan mengelola sampah secara efektif (Futurarch, 2008). Terminal bus dan pusat perbelanjaan yang direncanakan menggunakan kriteria dan tolak ukur berdasarkan Green Building Council Indonesia (2014), yaitu:

Tabel 1. Kriteria dan Tolak Ukur Green Building Council Indonesia

\begin{tabular}{|c|c|c|}
\hline No & Kriteria & Tolak Ukur \\
\hline 1 & $\begin{array}{l}\text { Pemilihan } \\
\text { Tapak }\end{array}$ & $\begin{array}{l}\text { Derah bangunan memiliki } \\
\text { minimal delapan dari } 12 \text { sarana } \\
\text { prasarana kota (jaringan jalan, } \\
\text { jaringan penerangan dan listrik, } \\
\text { jaringan drainase, jaringan fiber } \\
\text { optik, jaingan telepon, jaringan } \\
\text { air bersih, jalur pejalan kaki } \\
\text { kawasan, jalur pemipaan gas, } \\
\text { danau buatan, STP kawasan, } \\
\text { sistem pembuangan sampah, dan } \\
\text { sistem pemadam kebakaran). }\end{array}$ \\
\hline 2 & $\begin{array}{lr}\text { Area } & \text { Dasar } \\
\text { Hijau } \quad \& \\
\text { Lansekap } \\
\text { pada Lahan }\end{array}$ & $\begin{array}{l}\text { Terdapat lansekap yang berupa } \\
\text { vegetasi (softscape) yang bebas } \\
\text { dari bangunan dan taman } \\
\text { (hardscape) di atas atau bawah } \\
\text { permukaan tanah. }\end{array}$ \\
\hline 3 & $\begin{array}{l}\text { Aksesibilitas } \\
\text { Komunitas }\end{array}$ & $\begin{array}{l}\text { Tersedia akses bagi pejalan kaki } \\
\text { yang aman dan nyaman. }\end{array}$ \\
\hline 4 & $\begin{array}{l}\text { Fasilitas } \\
\text { Pengguna } \\
\text { Sepeda }\end{array}$ & Tersedia tempat parkir sepeda. \\
\hline 5 & Iklim Mikro & $\begin{array}{l}\text { Menggunakan green roof seluas } \\
50 \% \text { dari luas atap dihitung dari } \\
\text { luas tajuk. }\end{array}$ \\
\hline & & $\begin{array}{l}\text { Terdapat pelindung dari panas } \\
\text { pada area pejalan kaki }\end{array}$ \\
\hline 6 & $\begin{array}{l}\text { Perhitungan } \\
\text { OTTV }\end{array}$ & $\begin{array}{l}\text { Menggunakan cara perhitungan } \\
\text { OTTV berdasarkan SNI 03-6389- } \\
2011 \text { atau yang terbaru mengenai } \\
\text { Konservasi Energi Selubung } \\
\text { Bangunan. }\end{array}$ \\
\hline 7 & $\begin{array}{l}\text { Kendali Asap } \\
\text { Rokok di } \\
\text { Lingkungan }\end{array}$ & $\begin{array}{l}\text { Memasang tanda "Dilarang } \\
\text { Merokok di Seluruh Area } \\
\text { Gedung" dan menyediakan } \\
\text { ruangan khusus merokok dengan } \\
\text { bukaan jendela }\end{array}$ \\
\hline 8 & Ventilasi & $\begin{array}{l}\text { Tidak membei AC pada ruang } \\
\text { WC, tangga, koridor, dan lobi lift } \\
\text { dan menggantinya dengan } \\
\text { ventilasi alami maupun mekanik }\end{array}$ \\
\hline 9 & $\begin{array}{l}\text { Manajemen } \\
\text { Air Limpasan } \\
\text { Hujan }\end{array}$ & $\begin{array}{l}\text { Pengurangan beban limpasan air } \\
\text { hujan dari bangunan ke jaringan } \\
\text { drainase kota. }\end{array}$ \\
\hline 10 & $\begin{array}{l}\text { Penampungan } \\
\text { Air Hujan }\end{array}$ & $\begin{array}{l}\text { Menyediakan instalasi tangki } \\
\text { penampungan air hujan dengan } \\
\text { kapasitas } 50 \% \text { jumlah air hujan } \\
\text { yang jatuh di atas atap. }\end{array}$ \\
\hline
\end{tabular}




\begin{tabular}{lll}
\hline 11 & $\begin{array}{l}\text { Efisiensi } \\
\text { Penggunaan } \\
\text { Air Lansekap }\end{array}$ & $\begin{array}{l}\text { Seluruh air yang digunakan untuk } \\
\text { irigasi gedung tidak berasal dari } \\
\text { air tanah dan/atau PDAM. }\end{array}$ \\
\hline 12 & $\begin{array}{l}\text { Efisiensi dan } \\
\text { Konservasi } \\
\text { Energi }\end{array}$ & $\begin{array}{l}\text { Zonasi pencahayaan ruang kerja } \\
\text { menggunakan sensor gerak. }\end{array}$ \\
\cline { 3 - 4 } & & $\begin{array}{l}\text { Penempatan tombol lampu dalam } \\
\text { jarak pencapaian tangan saat } \\
\text { membuka pintu. }\end{array}$ \\
\cline { 3 - 4 } & & $\begin{array}{l}\text { Menggunakan fitur hemat energi } \\
\text { pada lift, sensor gerak atau sleep } \\
\text { mode pada eskalator. }\end{array}$ \\
\hline 13 & $\begin{array}{l}\text { Dasar } \\
\text { Pengelolaan } \\
\text { Sampah }\end{array}$ & $\begin{array}{l}\text { Tersedia instalasi untuk memilah } \\
\text { dan mengumpulkan sampah } \\
\text { berdasarkan jenis organik, } \\
\text { anorganik, dan B3. }\end{array}$ \\
\hline
\end{tabular}

Sumber: Green Building Council Indonesia, 2014

\subsection{Terminal Bus}

Terminal bus adalah prasarana yang digunakan oleh angkutan jalan raya untuk mengatur pemberangkatan serta kedatangan, tempat pemangkalan kendaraan umum, menurunkan atau memuat barang dan atau penumpang (Morlok dalam Budhianto, 2014). Salah satu tipe terminal yang ada yaitu Tipe B di mana terminal tersebut memiliki peran utama dalam melayani kendaraan umum untuk angkutan perdesaan dan atau angkutan perkotaan serta angkutan antarkota antarprovinsi. Terminal memiliki fungsi yang dijelaskan menurut Morlok (1991), yaitu:

a. Tempat menaikkan dan menurunkan penumpang dan atau barang antar kendaraan,

b. Tempat menampung penumpang dan atau barang dari waktu tiba sampai waktu keberangkatan dengan menyediakan kenyamanan bagi penumpang,

c. Tempat penyimpanan dan tempat pemeliharaan kendaraan,

d. Tempat menyiapkan perlengkapan perjalanan,

e. Tempat pengelompokkan penumpang dan atau barang sesuai tujuan.

\subsection{Pusat Perbelanjaan}

Pusat perbelanjaan merupakan bangunan yang memiliki satu atau lebih department store sebagai daya tarik retail-retail dengan tipologi bentuk ruang yang menghadap ke koridor, di mana koridor adalah unsur utama pada pusat perbelanjaan yang berfungsi sebagai sirkulasi dan ruang komunal untuk berinteraksi antara penjual dan pembeli (Maitland dalam Purbandini, 2011). Berdasarkan skala pelayanannya, pusat perbelanjaan diklasifikasikan dalam beberapa bentuk. Salah satunya adalah regional center sebagai pusat perbelanjaan skala wilayah, anchor tenant sebagai pusat and toko-toko lainnya, serta memiliki fasilitas parkir yang cukup luas (International Council of Shopping Center dalam Rianto, 2016).

\section{METODE}

Metode penelitian diawali dengan adanya fenomena tentang terminal bus dan pusat perbelanjaan di Kabupaten Karanganyar yang selanjutnya dapat dilakukan pengumpulan pustaka dan data lapangan. Analisis dan pembahasan dilakukan untuk menghasilkan desain terminal bus dan pusat perbelanjaan yang sesuai dengan prinsip arsitektur hijau. Analisis yang dilakukan terdiri dari:

\subsection{Analisis Tapak}

Analisis tapak berisi uraian tentang kondisi pada eksisting tapak, yang meliputi lokasi tapak, potensi tapak, batas-batas tapak, sirkulasi pada tapak, pencapaiaan menuju dan keluar tapak, vegetasi, kondisi iklim, dan peraturan yang berlaku pada tapak.

\subsection{Analisis Arsitektur Hijau pada Desain Bangunan}

Analisis arsitektur hijau pada elemen bengunan yang dapat diterapkan pada terminal bus dan pusat perbelanjaan.

\subsection{Analisis Utilitas}

Analisis utilitas berupa uraian beberapa sistem utilitas seperti sistem penyediaan air bersih, sistem jaringan listrik, sistem drainase, dan sistem keamanan yang dapat diterapkan pada terminal bus dan pusat perbelanjaan.

\section{HASIL DAN PEMBAHASAN}

\subsection{Pemilihan Tapak}

Lokasi tapak berada di Jalan Raya Solo-Ngawi, Kebakkramat, Kabupaten Karanganyar yang memiliki luas $102.871 \mathrm{~m}^{2}$ dengan kondisi tanah yang relatif datar. Di lokasi tersebut terdapat beberapa prasarana antara lain jaringan jalan, jaringan penerangan dan listrik, jaringan drainase, jaringan fiber optik, jaringan telepon, jaringan air bersih, sistem pembuangan sampah, dan sistem pemadam kebakaran. Pemilihan 
tapak didasarkan pada kriteria dan tolak ukur Green Building Council Indonesia (2014) di mana tapak yang dipilih harus memiliki beberapa tolak ukur seperti daerah bangunan memiliki minimal delapan dari 12 prasarana kota antara lain jaringan jalan, jaringan penerangan dan litrik, jaringan drainase, jaringan fiber optik, jaringan telepon, jaringan air bersih, jalur pejalan kaki kawasan, jalur pemipaan gas, danau buatan, STP kawasan, sistem pembuangan sampah, dan sistem pemadam kebakaran.

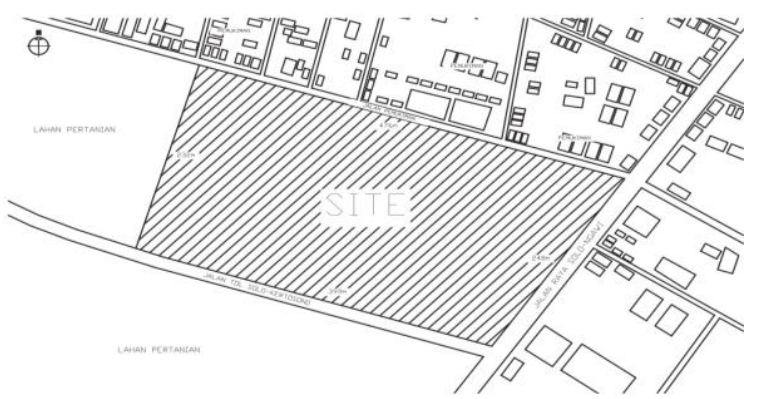

Gambar 1. Lokasi Tapak Terpilih

\subsection{Dasar Hijau dan Lansekap pada Lahan}

Jalur sirkulasi kendaraan ditanami pohon palem yang dapat digunakan sebagai pohon pengarah, peneduh, dan penyaring polusi udara. Pohon ketapang diterapkan pada area parkir sebagai peneduh dan pohon cemara atau palem sebagai pengarah. Pada area perbatasan menggunakan pohon cemara dan palem sebagai penyaring dari polusi udara dan pembatas, serta pada sekeliling bangunan dilindungi dengan dinding yang mengaplikasikan green wall. Lansekap yang berupa vegetasi dan taman diperlukan untuk mengurangi paparan sinar matahari secara langsung yang mengakibatkan lingkungan bangunan terasa panas karena tidak terdapat peneduh. Selain itu, polusi udara dari kendaraan tidak terserap jika tidak terdapat tanaman. Pada area terbuka dapat diaplikasikan taman dan kolam sebagai penambah estetika pada lansekap dan penyetabil suhu kawasan.

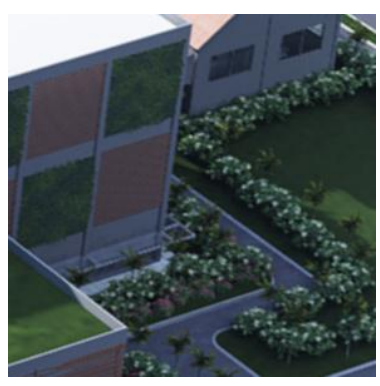

\section{Gambar 2. Green Wall dan Vegetasi}

\subsection{Aksesibilitas Komunitas}

Area khusus pejalan kaki yang terpisah dari jalur kendaraan disediakan untuk pengguna yang berjalan kaki. Pengguna yang berjalan kaki menuju bangunan memerlukan fasilitas yang nyaman untuk digunakan pada area tapak dan terhindar dari kendaraan agar keamanan pengguna terjaga.

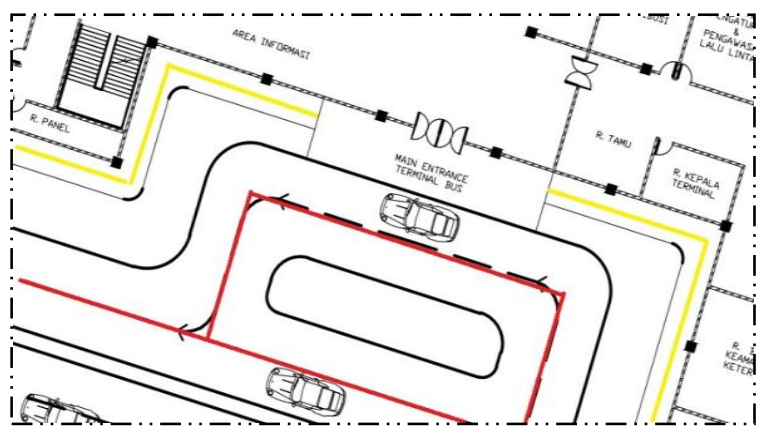

Gambar 3. Jalur Pejalan Kaki (kuning) yang Terpisah dengan Jalur Kendaraan (merah)

\subsection{Fasilitas Pengguna Sepeda}

Tempat parkir sepeda yang disediakan maksimal berjumlah 100 unit (Green Building Council Indonesia, 2014) untuk pengguna yang menggunakan sepeda karena kendaraan pribadi pengguna tidak hanya motor atau mobil, namun juga sepeda.

\subsection{Iklim Mikro}

a. Roof garden pada atap pusat perbelanjaan diaplikasikan untuk menurunkan suhu bangunan dan mereduksi udara yang terkena polusi akibat kendaraan bermotor. Karbon monoksida dari asap kendaraan bermotor dapat menyebabkan polusi udara dan udara menjadi panas.

b. Pelindung/kanopi diaplikasikan pada jalur pejalan kaki agar terlindung dari sinar matahari. Sinar matahari menyebabkan pejalan kaki tidak nyaman ketika harus 
berjalan di jalur pejalan kaki tanpa pelindung.

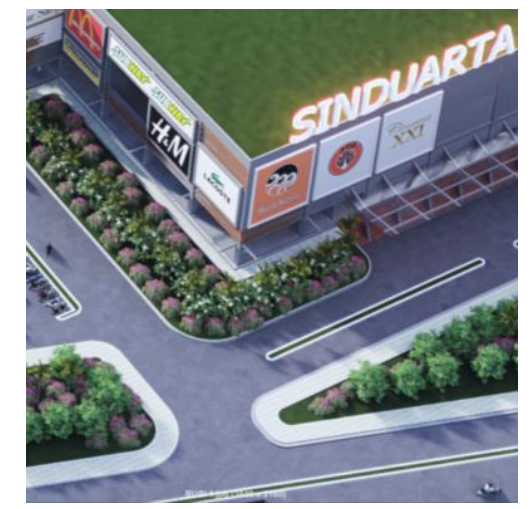

Gambar 4. Roof Garden dan Kanopi untuk Jalur Pejalan Kaki

\subsection{Perhitungan OTTV}

Panas matahari dapat masuk ke dalam bangunan jika dinding terlalu banyak menyerap cahaya matahari. Agar panas matahari yang diserap tidak terlalu banyak dibutuhkan material bangunan dan lapisan cat yang memiliki daya serap rendah dan daya pantul tinggi.

Permukaan semen memiliki daya serap 40-60\% dan daya pantul 60-40\%. Bata merah memiliki daya serap 60-75\% yang lebih rendah dari bata ekspos dan batu karang serta daya pantul 40$25 \%$. Warna cat putih memiliki daya serap 20$30 \%$ dan daya pantul $80-70 \%$ dan hijau muda memiliki daya serap 50-60\% dan daya pantul $50-40 \%$. Warna cat putih dan hijau muda memiliki daya serap yang lebih rendah dan daya pantul lebih tinggi dibanding warna cat lain.

Material bata merah dengan semen diaplikasikan sebagai material dinding karena memiliki daya serap rendah dan daya pantul tinggi. Warna cat yang terang seperti putih dan hijau muda diaplikasikan karena memiliki daya serap rendah dan daya pantul tinggi.

\subsection{Kendali Asap Rokok di Lingkungan}

Area merokok disediakan di dalam bangunan dalam ruangan khusus dengan bukaan jendela. Di luar area merokok diberi tanda "Dilarang Merokok" agar asap rokok tidak mengganggu pengguna lain karena asap rokok dapat menyebabkan polusi udara dan mengganggu pernapasan.

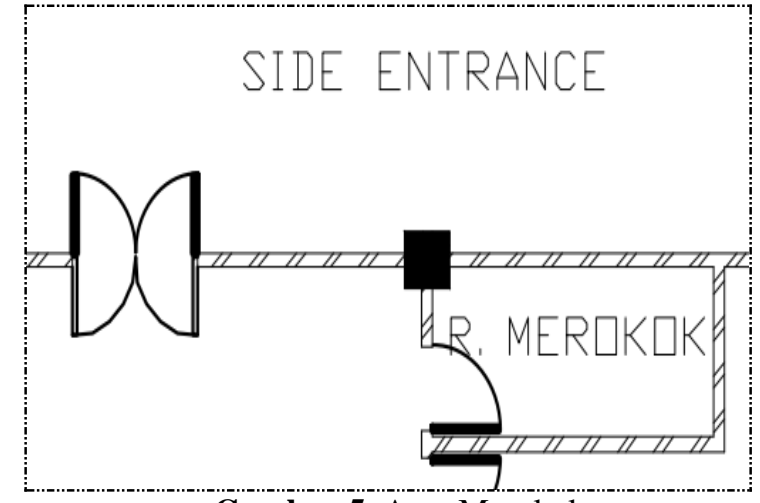

Gambar 5. Area Merokok

\subsection{Ventilasi}

Penghawaan alami digunakan sebagai alternatif dalam mengurangi penggunaan AC. Udara alami dimanfaatkan dengan mengaplikasikan ventilasi silang dalam bentuk kisi-kisi pada ruang-ruang servis seperti kamar mandi, koridor, dan tangga. Sedangkan penghawaan buatan menggunakan AC sentral yang diaplikasikan pada ruangan yang membutuhkan kenyamanan termal dengan pengaturan suhu pada masing-masing ruang.

Sistem penghawaan alami dan buatan diaplikasikan pada bangungan karena bangunan membutuhkan sirkulasi udara yang baik agar pengguna merasa nyaman. Cahaya matahari yang masuk akan membuat bangunan terasa panas jika di dalamnya tidak terdapat penghawaan.

\subsection{Manajemen Air Limpasan Hujan}

Air hujan yang langsung jatuh di tanah dibuatkan resapan (biopori) agar mudah meresap ke tanah. Air hujan yang jatuh di halaman kedap air dibuatkkan aliran air hujan yang mengelilingi bangunan agar tidak menggenang yang kemudian disalurkan ke riol kota. Air hujan yang jatuh di atap dibuatkan lubang-lubang menuju tangki penampungan air hujan sehingga air tersebut dapat dimanfaatkan untuk menyiram tanaman di area tapak. Pengolahan air hujan dibutuhkan karena air hujan yang jatuh tidak hanya langsung jatuh ke tanah namun juga jatuh ke halaman di sekitar tapak dan atap, sehingga air akan menggenang jika tidak diolah. Selain itu, air hujan yang diolah dapat dimanfaatkan untuk menyiram tanaman di area tapak. 


\subsection{Penampungan Air Hujan}

Instalasi penampungan air hujan dibuat untuk menampung air hujan yang jatuh di atap bangunan sehingga dapat dimanfaatkan untuk menyiram tanaman yang kemudian disalurkan ke tanah.

\subsection{Efisiensi Penggunaan Air Lansekap}

Sistem down feed diaplikasikan untuk sistem distribusi air bersih pada bangunan. Sistem ini tidak bekerja secara terus menerus karena terdapat penampungan air sehingga pompa yang digunakan lebih awet. Terminal bus dan pusat memiliki kebutuhan air yang tidak sedikit dan terus menerus bagi pengguna. Penggunan air yang terus menerus membutuhkan sistem air bersih yang efisien dan tahan lama. Air yang digunakan berasal dari PDAM dan sumur sehingga tidak mengeksploitasi salah satu sumber air.

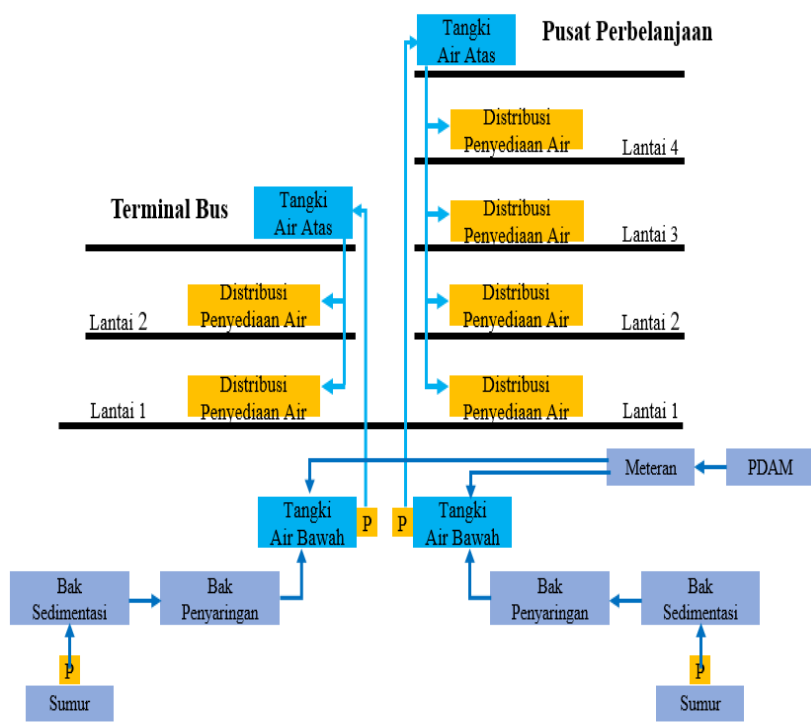

Diagram 3. Sistem Distribusi Air Bersih

Distribusi air kotor pada bangunan menerapkan sistem pembuangan terpisah serta pengaliran sistem grafitasi. Air bekas yang berasal dari air bekas mandi, air bekas cuci tangan, dan air bekas wudhu dialirkan menuju bak kontrol dengan perangkap udara yang kemudian dialirkan menuju riol kota dan ke dalam tanah melalui rembesan. Air limbah yang berasal dari kloset dan urinal diolah terlebih dahulu pada STP(Sewage Treatment Plant) kemudian masuk ke tanah melalui rembesan. Air limbah khusus yang berasal dari limbah dapur dialirkan menuju bak kontrol dengan perangkap lemak (grease trap) dan ditambahkan lubang kontrol (clean out) untuk pembersihan yang kemudian dialirkan menuju riol kota dan ke dalam tanah melalui rembesan.

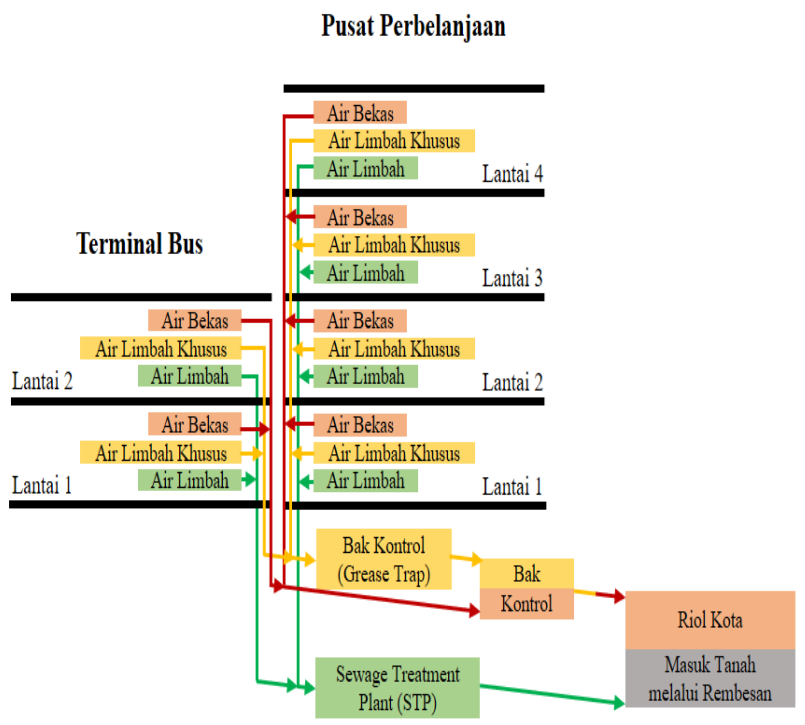

Diagram 4. Sistem Distribusi Air Kotor

\subsection{Efisiensi dan Konservasi Energi}

Cahaya matahari yang tersedia dari pagi hingga sore hari dapat dimanfaatkan sebagai pencahayaan alami dengan mengaplikasikan atap skylight agar cahaya dapat masuk ke dalam ruangan. Cahaya yang masuk dari samping dapat diatur intensitasnya dengan mengaplikasikan bukaan dengan sunscreen agar terhindar dari energi panas yang berlebihan, serta mengaplikasikan void agar cahaya yang masuk melalui atap skylight dan bukaan kaca dapat diteruskan. Namun cahaya matahari yang masuk secara langsung dapat menyebabkan silau, maka diaplikasikan pembayangan dengan sun shading dan secondary skin. Selain pencahayaan alami, pencahayaan buatan dibutuhkan untuk area yang tidak dapat menerima cahaya matahari dengan mengaplikasikan lampu hemat energi pada semua area ruangan dan lampu tenaga surya pada area lansekap sehingga mengurangi penggunaan daya listrik.

Sistem sirkulasi vertikal pada terminal bus mengaplikasikan ramp dan tangga untuk memudahkan pengguna mengakses lantai satu dengan lainnya. Sedangkan sistem sirkulasi vertikal pada pusat perbelanjaan mengaplikasikan sistem lift yang menggunakan fitur hemat energi, eskalator dan travelator dengan sleep mode, dan tangga. Terminal bus 
dan pusat perbelanjaan yang direncanakan memiliki jumlah lantai lebih dari satu, sehingga pengguna membutuhkan fasiitas untuk mengakses lantai satu dengan lainnya dengan mudah. Berdasarkan kriteria dan tolak ukur Green Building Council Indonesia (2014), sistem sirkulasi yang digunakan harus efisien dan hemat energi sehingga juga dapat mengurangi biaya perawatan yang dikeluarkan.

\subsection{Dasar Pengelolaan Sampah}

Terminal bus dan pusat perbelanjaan adalah fasilitas publik di mana banyaksampah bermacam-macam seperti sampah organik, anorganik, dan B3. Untuk menanggulanginya, disediakan fasilitas pembuangan sampah sesuai dengan jenis sampah yang diletakkan pada area yang mudah dijangkau. Sampah yang berada di setiap lantai membutuhkan sistem pembuangan yang dapat melayani seluruh lantai secara langsung. Untuk itu, disediakan shaft pembuangan sampah dari lantai atas menuju ke lantai bawah.

\section{KESIMPULAN}

Pendekatan arsitektur hijau yang diterapkan pada terminal bus dan pusat perbelanjaan berdasarkan kriteria dan tolak ukur yang tercantum dalam Green Building Council Indonesia (2014). Berdasar kriteria dan tolak ukur untuk tapak, tapak terpilih berada di Jalan Raya Solo-Ngawi, Kebakkramat, Kabupaten Karanganyar dengan luas $102.871 \mathrm{~m}^{2}$.

Pepohonan ditanam di sekitar jalur sirkulasi kendaraan, area parkir, dan area perbatasan yang digunakan sebagai pengarah, peneduh, penyaring polusi udara, dan pembatas. Greenwall diaplikasikan sebagai pelindung dari sinar matahari. Taman dan kolam pada area terbuka diaplikasikan sebagai penambah estetika dan penyetabil suhu kawasan.

Area khusus pejalan kaki disediakan di sekitar bangunan yang terpisah dengan jalur kendaraan. Untuk pengguna yang menggunakan sepeda, disediakan tempat parkir sepeda maksimal berjumlah 100 unit.

Roof garden pada atap pusat perbelanjaan dan pelindung/kanopi pada jalur pejalan kaki diaplikasikan untuk mengurangi panas sinar matahari yang masuk ke bangunan. Material bata merah dengan semen diaplikasikan sebagai material dinding serta warna cat putih dan hijau sebagai warna cat dinding karena memiliki daya serap panas matahari yang rendah dan daya pantul tinggi.

Tanda dilarang merokok diperlukan agar pengguna tidak bebas merokok di dalam bangunan karena dapat mengganggu dan menyebabkan polusi udara. Maka dari itu, dipasanglah tanda "Dilarang Merokok" di area bangunan dan menyediakan ruangan khusus merokok dengan bukaan jendela. Kisi-kisi diaplikasikan pada ruang servis seperti kamar mandi/WC, koridor, dan tangga. Untuk penghawaan buatan, AC sentral diaplikasikan pada ruangan yang membutuhkan kenyamanan termal dengan pengaturan suhu pada masingmasing ruang.

Air hujan yang langsung jatuh ke tanah dibuatkan resapan (biopori), air hujan yang jatuh di halaman kedap air dibuatkan aliran air hujan yang mengelilingi bangunan dan disalurkan ke riol kota. Air hujan yang jatuh di atap dibuatkan lubang-lubang menuju tangki penampungan air hujan sehingga air tersebut dapat digunakan untuk menyiram tanaman di area tapak.

Sistem down feed digunakan dalam distribusi air bersih dengan sumber air yang berasal dari PDAM dan sumur. Distribusi air kotor pada bangunan menerapkan sistem pembuangan terpisah serta pengaliran sistem grafitasi. Air bekas yang berasal dari air bekas mandi, air bekas cuci tangan, dan air bekas wudhu dialirkan menuju bak kontrol dengan perangkap udara yang kemudian dialirkan menuju riol kota dan ke dalam tanah melalui rembesan. Air limbah yang berasal dari kloset dan urinal diolah terlebih dahulu pada STP (Sewage Treatment Plant) kemudian masuk ke tanah melalui rembesan. Air limbah khusus yang berasal dari limbah dapur dialirkan menuju bak kontrol dengan perangkap lemak (grease trap) dan ditambahkan lubang kontrol (clean out) untuk pembersihan yang kemudian dialirkan menuju riol kota dan ke dalam tanah melalui rembesan. Atap skylight, void, bukaan kaca diaplikasikan agar cahaya matahari dapat masuk ke dalam bangunan. Untuk mengatur intensitas cahaya, diaplikasikan bukaan dengan sunscreen, sun shading, dan secondary skin. Lampu hemat energi diaplikasikan pada semua area ruangan 
dan lampu tenaga surya pada area lansekap sebagai pencahayaan buatan pada bangunan.

Sistem sirkulasi vertikal pada terminal bus mengaplikasikan ramp dan tangga, sedangkan pada pusat perbelanjaan mengaplikasikan lift dengan fitur hemat energi, eskalator dan travelator dengan slep mode, dan tangga.

Jenis sampah yang terdapat di terminal bus dan pusat perbelanjaan seperti sampah organik, anorganik, dan B3 dibuang dengan memisahkan sampah sesuai jenisnya dan menyediakan shaft pembuangan sampah di setiap lantai.

\section{REFERENSI}

Budhianto, A. (2014). Landasan Konseptual Perencanaan dan Perancangan Terminal Bus Induk Tipe A di Kabupaten Klaten. Skripsi.

Dewi, T. H., Nirawati, M. A., \& Handayani, K. N. (2015). Taman Bermain dengan Pendekatan Arsitektur Hijau di Sukoharjo. Arsitektura 13(1).

Dina, A. N. (2014). Redesain Terminal Kartasura. Skripsi.

Divisi Rating dan Teknologi Green Building Council Indonesia. (2013). Greenship untuk Bangunan Baru Versi 1.2 Ringkasan Kriteria dan Tolok Ukur. Jakarta: GBCI

Futurarch. (2008). "Paradigma Arsitektur Hijau", Green Lebih dari Sekedar Hijau. $3(2)$.

Morlok, E. K. (1991). Pengantar Teknik dan Perencanaan Transportasi. Jakarta: Erlangga.

Purbandini, R. A. (2011). Konsep Perencanaan dan Perancangan Hotel dan Shopping Mall di Purwokerto dengan Pendekatan Arsitektur Hijau. Skripsi.

Prisamsiwi, N. A., Santosa, B. H., \& Pramesti, L. (2015). Redesain Terminal Tironadi dengan Pendekatan Green Terminal di Surakarta. Arsitektura 13(1).

Rianto, A. D. (2016). Landasan Program Perencanaan dan Perancangan Arsitektur Pusat Perbelanjaan Berkonsep Citywalk di Kota Bogor. Skripsi.

Sutandi, A. C. (2015). Pentingnya Transportasi Umum untuk Kepentingan Publik. Jurnal Administrasi Publik 12(1). 